\title{
LOS HILOS DE LA TRAMA OSCURA: LA DIVERSIDAD TEOLÓGICA EN LA POESÍA DE BORGES
}

Pablo NúÑez Díaz

UNED. Asturias

ndpablo@gijon.uned.es

\section{RESUMEN}

El objetivo de este artículo es mostrar el carácter heterogéneo de las referencias teológicas que aparecen en los poemas de Jorge Luis Borges. En ellos, el autor aborda literariamente $-\mathrm{y}$ a veces transforma- temas relacionados con la historia sagrada y con doctrinas de distintas tradiciones eclesiales. Se hará especial hincapié en la pluralidad de ideas soteriológicas y escatológicas. Por otro lado, a pesar del agnosticismo de Borges, la voz que habla en sus poemas se muestra en ocasiones como creyente, mientras que otras veces expresa sus dudas o claramente su incredulidad.

Palabras Clave: Borges. Poesía. Teología. Biblia. Cristianismo. Judaísmo.

\section{Abstract}

The aim of this paper is to show the heterogeneous character of the theological references that appear in Jorge Luis Borges's poems. The author approaches them as literature, and sometimes transforms topics related to sacred history and doctrines from different ecclesial traditions. We will put special emphasis on the plurality of soteriological and eschatological ideas. Despite Borges' agnosticism, the voice that speaks in his poems displays at times a believer's concern, while at other times it reveals his doubts or sheer incredulity.

KeY wORDs: Borges. Poetry. Theology. Bible. Christianism. Judaism. 
La teología está presente en buena parte de los versos más hondos y memorables de Jorge Luis Borges. Su obra poética no sería la misma sin las referencias a la relación entre Dios y ser humano, el libre albedrío, la predestinación o la expiación. Tampoco podría entenderse sin dos rasgos que hacen que la historia sagrada reviva en su poesía -en ocasiones totalmente transformada-: la recreación de escenas bíblicas y el protagonismo de personajes tanto del Antiguo como del Nuevo Testamento. Su curiosidad intelectual le llevó a tratar literariamente las creencias y los dogmas, desde la distancia propia de su agnosticismo (por ejemplo, acerca de su transformación del relato de Caín y Abel, vid. Aizenberg, 1986: 118-128).

La relación del escritor con el hecho religioso no fue en absoluto homogénea, debido sobre todo a la influencia de su familia inglesa. La educación del autor estuvo en gran medida a cargo de su abuela paterna, Frances Anne Haslam, de fe protestante, que le inculcó su pasión por la Biblia. La madre de Borges, Leonor Acevedo, provenía en cambio de una familia católica, que también influyó de algún modo en la cultura religiosa del narrador y poeta, aunque más determinante fue sin duda el escepticismo de su padre, Jorge Guillermo Borges.

En este breve estudio nos centraremos fundamentalmente en dos de los aspectos que evidencian la pluralidad de ideas teológicas en la poesía del autor, i. e., las alusiones a las doctrinas cristianas sobre la salvación del hombre y la escatología. La propia herencia protestante de Borges era en sí misma diversa en lo que tiene que ver con la soteriología, al integrar conceptos calvinistas y arminianos ${ }^{1}$. En cuanto a la esperanza post mortem, en su obra poética aparecen tanto doctrinas propias del cristianismo como de otros trasfondos religiosos y filosóficos.

El tatarabuelo de Borges, William Haslam (1768-1839), ejerció como pastor de la Nueva Conexión Metodista ${ }^{2}$, que en el aspecto soteriológico seguía mayoritariamente la enseñanza no calvinista del fundador del metodismo, John Wesley. Sólo una parte de los metodistas, influidos por uno de los principales colaboradores de Wesley, George Whitefield, se decantaron por el calvinismo y se organizaron de forma independiente al resto (vid. Léonard, 1967: 113 y MacCulloch, 2011: 805).

La figura de William Haslam marcó a su familia en lo que se refiere a las creencias y a la inquietud intelectual. Su hijo Edward Young Haslam, bisabuelo de Borges, se doctoró en Filosofía y Letras por la Universidad de Heidelberg y se dedicó a la enseñanza. Edward Young no tuvo la vocación religiosa de su progenitor, y parece que se integró en la sociedad de su tiempo como un anglicano más ${ }^{3}$. Las diferencias doctrinales entre el metodismo y la Iglesia de Inglaterra no eran difíciles de salvar (especialmente en la

${ }^{1}$ Con el término «arminianismo» me referiré a la corriente protestante que niega el monergismo de Lutero y, sobre todo, de Calvino, que enseñaban que el ser humano no podía poner nada de su parte en el camino hacia la salvación. Para ellos, hasta el propio acto de creer era un don de Dios en el que el hombre no intervenía de ningún modo. Así pues, haré referencia al arminianismo por lo que esencialmente le caracteriza en el ámbito protestante, esto es, su negación de la predestinación calvinista, sin detenerme en otros matices doctrinales. Sobre la soteriología del teólogo que da nombre a dicha corriente, Jacobus Arminio (1560-1609), vid., por ejemplo, White, 2002: 13 y ss.

${ }_{2}$ Para conocer detalles de la biografía del reverendo Haslam, vid. Allin et alii, 1848: 49-51 y, especialmente, Hadis, 2006: 81-104.

3 Acerca de su paso del metodismo al anglicanismo, y de su vida en Argentina a partir de la década de 1870, vid. Hadis, 2006: 265 y ss. 
tendencia low church del anglicanismo, que no deja de ser otra rama del protestantismo evangélico). En la confesión de fe de la Iglesia de Inglaterra, los llamados 39 Artículos, se afirma la predestinación de forma moderada, y en ningún caso la doble predestinación de Calvino ${ }^{4}$, de ahí que la soteriología de Wesley tenga cabida en el seno de dicha denominación. Asimismo, el metodismo retuvo el bautismo de infantes y no consideró la presencia real de Cristo en la Eucaristía como meramente simbólica, dos aspectos en los que se mantuvo en consonancia con la doctrina anglicana.

La visión soteriológica del catolicismo no es menos compleja. Recuérdense las divergencias entre molinistas y tomistas. Sin embargo, existe un consenso elemental opuesto a la doble predestinación. Para el catolicismo, «[1]a justificación establece la colaboración entre la gracia de Dios y la libertad del hombre ${ }^{5}$ » (VV. AA., 1992: 443).

La diversidad de este contexto religioso se vio acentuada por la atracción que Borges sentía hacia otras creencias, por sus lecturas, sus relaciones personales, sus viajes (España, Estados Unidos, Israel, Reino Unido...), y sin duda por su etapa de estudiante de bachillerato en el Lycée Jean Calvin de Ginebra, ciudad en la que también pasó los últimos meses de su vida y en la que descansan sus restos, en el cementerio de Plainpalais, a escasos metros de los del reformador francés.

A todo ello debe añadirse la pasión por la filosofía, que enriqueció su obra de forma paralela a las doctrinas relacionadas con la divinidad. «La filosofía y la teología son, lo sospecho, dos especies de la literatura fantástica. Dos especies espléndidas», llegó a afirmar en la nota al poema «Las catedrales», de su libro La cifra (1981) (Borges, 2011c: 577). Ha de tenerse en cuenta, además, el interés de Borges por el judaísmo, así como su compromiso en la denuncia del Holocausto (vid. Aizenberg, 1986: 25-29) y de las persecuciones de los judíos en la Argentina de Perón (vid. Aizenberg, 1986: 41-42).

A continuación nos detendremos en distintos ejemplos de la poesía ${ }^{6}$ de Borges que muestran, de forma significativa, la diversidad de referencias teológicas, en su mayor parte relacionadas con la salvación y con la esperanza post mortem, como se ha mencionado.

\section{Sobre LA SALVACióN}

La muerte de Jesús, como punto central de la doctrina cristiana de la expiación, no podía pasarle desapercibida al Borges poeta. En sus versos aparecen alusiones a la ejecución del Mesías, por ejemplo en dos poemas de El otro, el mismo (1964): «Baltasar

\footnotetext{
${ }^{4}$ En su Institución de la religión cristiana, Calvino sostiene que Dios, por medio de su «eterno decreto», «ordena a unos para la vida eterna, y a otros para condenación perpetua» (Calvino, 2003: 728-729). Sobre las dos principales interpretaciones reformadas de esta enseñanza, conocidas como calvinismo supralapsario e infralapsario -según consideren al objeto de la condenación como homo creabilis et labilis o como homo creatus et lapsus, respectivamente-, vid. Barth, 2004: 127-145.

${ }^{5}$ En cursiva en el original.

${ }^{6}$ La importancia de la diversidad teológica también resulta evidente en su narrativa y en sus escritos de carácter ensayístico. Vid., por ejemplo, sus relatos «Tres versiones de Judas» (Borges, 2011a: 200-205), «Los teólogos» (Borges, 2011a: 245-253), «La Secta de los Treinta» (Borges, 2011a: 465-468) o «El libro de arena» (Borges, 2011a: 506-510).
} 
Gracián» («...no vio al fatal Edipo en el exilio / ni a Cristo que se muere en un madero») (Borges, 2011c: 189) y «Otro poema de los dones» («...por las palabras que en un crepúsculo se dijeron / de una cruz a otra cruz» (Borges, 2011c: 249). El tema que nos ocupa tiene especial importancia en «El Oriente», de La rosa profunda (1975), y en «Cristo en la cruz», de Los conjurados (1985). En el primero de ellos, Borges menciona la historia del Calvario como parte de su Oriente, del jardín que tiene «para que tu memoria no me ahogue»:

En un atardecer muere un judio / crucificado por los negros clavos / que el pretor ordenó, pero las gentes / de las generaciones de la tierra / no olvidarán la sangre y la plegaria / y en la colina los tres hombres últimos (ibid.: 425).

Por su parte, en «Cristo en la cruz», el autor reconstruye los últimos instantes de la vida de Jesús. En los dos últimos versos, Borges descree del valor real que aquella muerte pudo tener para sí mismo: «¿De qué puede servirme que aquel hombre / haya sufrido, si yo sufro ahora?» (Borges, 2011c: 586). El valor expiatorio es afirmado en cambio por el propio Jesús en otro de los poemas de Los conjurados, titulado «Otro fragmento apócrifo», en el que el maestro le dice a uno de sus discípulos, afligido por haber cometido un crimen años atrás: «Te incumben los deberes de todo hombre: ser justo y ser feliz. Tú mismo tienes que salvarte. Si algo ha quedado de tu culpa yo cargaré con ella» (Borges, 2011c: 620). La afirmación de que el discípulo tiene que salvarse a sí mismo no está en consonancia con la doctrina católica de la salvación, y menos aún con el principio protestante de sola fide. En cuanto a esta cuestión, ha de recordarse el poema «Lucas, XXIII», de El hacedor (1960), en el que «el candor» del buen ladrón hizo que «pidiera y ganara el Paraíso $^{7} »$ (Borges, 2011c: 147). La idea de «ganar el Paraíso» resulta incompatible con la soteriología de la Reforma.

En la poesía de Borges también aparecen al menos una veintena de referencias que tienen que ver con el destino del hombre, $v . g$., la existencia o no del libre albedrío, la presciencia de Dios, la predestinación, la Fortuna y el azar. De todo ello, lo que más atañe a la diversidad teológica es la predestinación. Dicha doctrina adquiere especial importancia en el poema «El general Quiroga va en coche al muere», del libro Luna de enfrente (1925):

Ya muerto, ya de pie, ya inmortal, ya fantasma, / se presentó al infierno que Dios le había marcado, / y a sus órdenes iban, rotas y desangradas / las ánimas en pena de hombres y de caballos (Borges, 2011c: 69).

Esta enseñanza estaba ya presente en el soneto «Jonathan Edwards (1703-1785 $\left.{ }^{8}\right)$ », de El otro, el mismo. La curiosidad de Borges por lo teológico queda patente en la elección del protagonista del poema: uno de los personajes de mayor relevancia en la historia del puritanismo. Edwards lideró como pastor un importante avivamiento de la fe

\footnotetext{
${ }^{7}$ En el caso de los nombres relacionados con la historia sagrada-como en el resto de términos-, respeto el uso de mayúscula y minúscula que aparece en cada texto citado.

${ }^{8}$ El año de la muerte de Edwards fue en realidad 1758.
} 
reformada en Nueva Inglaterra ${ }^{9}$, y sus escritos se encuentran entre lo más destacado de la literatura norteamericana de época colonial. Acerca de él, Borges escribe lo siguiente:

Piensa feliz que el mundo es un eterno / instrumento de ira y que el ansiado / cielo para unos pocos fue creado / y casi para todos el infierno (Borges, 2011c: 221).

En «El acto del libro», de La cifra (1981), Borges reinventa la historia de Alonso Quijano, cuyo destino se habría detallado en un libro mágico, «escrito en lengua arábiga, que un soldado adquirió por unas monedas en el Alcana de Toledo y que los orientalistas ignoran, salvo en la versión castellana» (Borges, 2011c: 526). En la parte final de este poema se plantea con toda crudeza el problema de la predestinación y el libre albedrío: «¿Acaso es más extraña esta fantasía que la predestinación del Islam que postula un Dios, o que el libre albedrío, que nos da la terrible potestad de elegir el infierno?» (Borges, 2011c: 526). En «Eclesiastés, I, 9», de la misma obra, Borges parte del versículo del Qohelet que le da título ${ }^{10}$ para relacionar el hecho de que no haya nada nuevo bajo el sol con la creencia en un destino fijado: «repito lo cumplido innumerables / veces en mi camino señalado. No puedo ejecutar un acto nuevo» (Borges, 2011c: 532). Recuérdese, en este sentido, el poema «Límites»-de El otro, el mismo-, cuyo protagonista se encuentra «sometido / a Quien prefija omnipotentes normas / y una secreta y rígida medida / a las sombras, los sueños y las formas / que destejen y tejen esta vida» (Borges, 2011c: 187).

Las últimas muestras que mencionaré de la soteriología del poeta, o del hablante poemático, son claramente heterodoxas. En «Casi juicio final», de Luna de enfrente, cifra su esperanza en la misericordia de la Luna: «Siento el pavor de la belleza; ¿quién se atreverá a condenarme si esta gran luna de mi soledad me perdona?» (Borges, 2011c: 76). En estos versos resuenan las palabras de San Pablo, que el poeta conocía bien: «¿Quién acusará a los escogidos de Dios? Dios es el que justifica. ¿Quién es el que condenará?» (Romanos 8, 33 y 34a) ${ }^{11}$. Borges parte de esta idea paulina para transformarla.

En «La moneda de hierro», del libro homónimo, no hay ni exaltación ni condena por parte de Dios, sino simplemente olvido (Borges, 2011c: 469), mientras que en «Ajedrez», de El hacedor, el autor se pregunta qué otra divinidad estará detrás de los actos de Dios, del mismo modo que Él está detrás de los nuestros: «Dios mueve al jugador, y éste, la pieza. / ¿Qué dios detrás de Dios la trama empieza / de polvo y tiempo y sueño y agonías» (Borges, 2011c: 116).

Por su parte, dos versos de «Browning resuelve ser poeta», de La rosa profunda, llevan a la conclusión de que Judas Iscariote cooperó con el plan de salvación al aceptar «la divina misión de ser traidor» (Borges, 2011c: 390) ${ }^{12}$, lo cual se aproxima a la reinterpretación que el grupo gnóstico de los cainitas llevó a cabo de la traición de Judas (sobre dicho grupo, vid. Wurst, 2006: 113-118). Actualmente se discute si el Evangelio

\footnotetext{
${ }^{9}$ En contraposición a la figura del protestante Jonathan Edwards, uno de los poemas de La moneda de hierro (1976) se centra en Olaus Magnus, «que no abjuró de Roma cuando el Norte / profesó las doctrinas de John Wyclif, de Hus y de Lutero» (Borges, 2011c: 458).

10 «Lo que pasó, eso pasará; lo que se hizo, eso se hará: nada hay nuevo bajo el sol», según leemos en la Biblia del peregrino de Luis Alonso Schökel.

${ }^{11}$ Cito de la revisión de la Reina-Valera contemporánea a dichas palabras de Borges, es decir, la que vio la luz en 1909 (C. de Reina y C. de Valera, 1909). La siguiente revisión data de 1960.

${ }^{12}$ Este mismo planteamiento aparece en el cuento «Tres versiones de Judas» (Borges, 2011a: 201 y 202).
} 
de Judas le adjudica a este apóstol el papel de ejecutor del encargo de Jesús (cf. Piñero, ed., 2009: 432-433), en la misma línea que los versos de Borges ${ }^{13}$.

\section{Escatología}

La poesía de Jorge Luis Borges es especialmente rica en alusiones a la muerte y a la enseñanza del cristianismo acerca del destino de los salvos y de los condenados. Sin embargo, en el poema que abre Fervor de Buenos Aires (1923), «La Recoleta», en el que reflexiona ante los sepulcros, «entre lentas filas de panteones», no hay atisbo de vida post mortem. En él leemos que cuando el alma se apague «se apagarán con ella el espacio, el tiempo y la muerte» (Borges, 2011c: 19). En este mismo sentido ha de entenderse la parte final de la composición:

Sombra benigna de los árboles, / viento con pájaros que sobre las ramas ondea, / alma que se dispersa en otras almas, / fuera un milagro que alguna vez dejaran de ser, / milagro incomprensible, / aunque su imaginaria repetición / infame con horror nuestros días. / Estas cosas pensé en la Recoleta, / en el lugar de mi ceniza (Borges, 2011c: 20).

De igual forma, en el poema «Llaneza», de la misma obra, «alcanzar lo más alto, lo que tal vez nos dará el Cielo», consiste para Borges en «ser admitidos / como parte de una Realidad innegable, / como las piedras y los árboles» (Borges, 2011c: 45). En su siguiente libro de poemas, Luna de enfrente, aparece la primera mención al Infierno en la poesía de Borges: se encuentra en «El general Quiroga va en coche al muere», en el cual el protagonista, ya en su condición de «inmortal» y «fantasma», acude a su destino sin perder la autoridad sobre las ánimas de sus hombres y de sus caballos (Borges, 2011c: 69).

En el poema «Del Infierno y del Cielo», de El otro, el mismo, Borges cuestiona la enseñanza tradicional acerca de ambos conceptos teológicos. En un sueño vislumbra que, cuando llegue el Juicio Final, «los colores y líneas del pasado / definirán en la tiniebla un rostro / durmiente, inmóvil, fiel, inalterable / (tal vez el de la amada, quizá el tuyo)» (Borges, 2011c: 174). La contemplación de ese rostro «será para los réprobos, Infierno; / para los elegidos, Paraíso» (Borges, 2011c: 174). En el libro mencionado, la «Composición escrita en un ejemplar de la «Gesta de Beowulf»» coincide igualmente con la creencia en la inmortalidad del alma (Borges, 2011c: 211); «El instante», en cambio, concluye con el mayor descreimiento: «El hoy fugaz es tenue y es eterno; / otro Cielo no esperes, ni otro Infierno» (Borges, 2011c: 228); mientras que en «Alguien» el poeta se plantea la posibilidad de que en la muerte lleguemos a ser «esa indescifrable raíz, / de la cual para siempre crecerá, / ecuánime o atroz, / nuestro solitario cielo o infierno» (Borges, 2011c: 239).

La parusía o segunda venida de Cristo, otro de los aspectos fundamentales de la escatología cristiana, aparece en «Lucas, XXIII», cuando el autor cita la súplica del ladrón directamente del versículo 42 del capítulo que da título al poema (en cursiva en el original): "Acuérdate de mí cuando vinieres / a tu reino, y la voz inconcebible / que un día juzgará a todos los seres / le prometió desde la Cruz terrible / el Paraíso»

${ }^{13}$ En cualquier caso, el autor firmó los versos en cuestión sin conocer el mencionado evangelio apócrifo, que fue descubierto en 1978, tres años después de la aparición de La rosa profunda, y no se publicó hasta 2006. 
(Borges, 2011c: 146). De nuevo una alusión teológica de Borges resulta más compleja de lo que a priori parecería: el poeta puede estar citando de la versión que el Padre Scío realizó de la Vulgata latina en el siglo XVIII (Scío de San Miguel, 1797), o bien de las revisiones de 1862 o 1909 de la traducción protestante Reina-Valera ${ }^{14}$. Por las conversaciones con Borges publicadas por Adolfo Bioy Casares, sabemos que tanto la del Padre Scío como la Reina-Valera eran dos de las versiones de la Escritura que ambos consultaban (Bioy Casares, 2006: 136).

En poemas posteriores se confirma la diversidad escatológica. Así, en «El tango», de El otro, el mismo, que parte del tópico ubi sunt, Borges se pregunta por el destino de Iberra, «(de quien los santos / se apiaden) que en un puente de la vía, / mató a su hermano el Ñato, que debía / más muertes que él, y así igualó los tantos» (Borges, 2011c: 196). Que los santos puedan tener piedad de los muertos, a la hora de compadecerse de ellos como paso previo a la intercesión, está en consonancia con la doctrina católica, pero no con la protestante, que no reconoce tal mediación. En dicha obra encontramos otro elemento propio del catolicismo: el Purgatorio, al que Borges se refiere en el «Otro poema de los dones» como «la torre del fuego que purifica» (Borges, 2011c: 250), en alusión a la Divina comedia de Dante.

También en El otro, el mismo destaca la creencia panteísta en que Dios es cada una de sus criaturas, lo que lleva a la conclusión de que Dios «sabe el sabor del fuego del infierno» por Caín («Él», Borges, 2011c: 207). Por su parte, en «Milonga de Manuel Flores», del libro Para las seis cuerdas (1965), aparece Cristo como el juez que espera al protagonista del poema tras la muerte (Borges, 2011c: 288); en «The unending rose», de La rosa profunda, se refiere a esta flor, «ilimitada, íntima, / que el Señor mostrará a mis ojos muertos» (Borges, 2011c: 428); y en la composición «A mi padre», de La moneda de hierro (1976), están presentes tanto la filosofía griega como el agnosticismo:

Nada esperabas ver del otro lado, / pero tu sombra acaso ha divisado / los arquetipos últimos que el griego / soñó y que me explicabas. Nadie sabe / de qué mañana el mármol es la llave (Borges, 2011c: 453).

En La cifra encontramos, por ejemplo, la afirmación de que recordar a los muertos es «inquietar su eternidad», «restituir al tiempo otro Lázaro / cargado de memoria» («Poema», Borges, 2011c: 555), así como una referencia al libro de Apocalipsis: «hasta el Último Día en que retumbe / el trueno en la trompeta» («El Ángel», Borges, 2011c: 556). También ha de mencionarse el poema «Inferno, V, 129», que nos remite a la $D i$ vina comedia y en concreto al círculo en que «pecadores carnales» como Francesca de Rímini y Paolo Malatesta ${ }^{15}$ reciben su castigo. Estos fueron a parar allí por su adulterio, al que les indujo la lectura de las aventuras de Lanzarote. «Un libro, un sueño les revela / que son formas de un sueño que fue soñado / en tierras de Bretaña. Otro libro hará que los hombres, / sueños también, los sueñen» (Borges, 2011c: 559), escribe Borges, situándonos de nuevo ante la problemática del destino.

\footnotetext{
${ }^{14}$ Otras versiones de la Biblia, también previas a la publicación de El hacedor, vierten las palabras del «buen ladrón» del siguiente modo: «when thou comest into thy kingdom» (King James version), «cuando hayas llegado a tu reino» (Torres Amat), «cuando entres en tu reino» (Nácar-Colunga) y «cuando vinieres en la gloria de tu realeza» (Bover-Cantera).

15 Dante no menciona el nombre de este último, pero la historia es conocida.
} 
Más allá incluso de las tres principales religiones monoteístas, la escatología del sintoísmo es central en «El forastero», incluido igualmente en La cifra. En este poema, un sacerdote sintoísta dice lo siguiente acerca de su «culto», que considera «el más leve y el más antiguo»: «Sabe que después de su muerte cada hombre es un dios que ampara a los suyos. / Sabe que después de su muerte cada árbol es un dios que ampara a los árboles» (Borges, 2011c: 571). Tampoco es acorde con la concepciones cristiana, judía e islámica el punto de vista del poema «Elegía de un parque», de Los conjurados, sobre la historia sin un principio ni un fin, es decir, circular, al modo del pensamiento griego, lo que es incompatible con la creación y el Juicio Final: «Si no hubo un principio ni habrá un término / si nos aguarda una infinita suma / de blancos días y de negras noches, / ya somos el pasado que seremos» (Borges, 2011c: 598).

\section{Otros ASPECTOS}

La obra poética de Borges también hace referencia a la divinidad de Jesucristo, tanto para afirmarla como para negarla. La afirmación se encuentra en los dos poemas titulados «Juan, I, 14»: en el primero de ellos, que forma parte de El otro, el mismo, «Dios quiere andar entre los hombres / y nace de una madre» (Borges, 2011c: 202), mientras que en el segundo, de Elogio de la sombra (1969), Jesús se presenta como «el Es, el Fue y el Será» (Borges, 2011c: 295). La negación aparece en «Cristo en la cruz», de Los conjurados, donde leemos: «Sabe que no es un dios y que es un hombre / que muere con el día» (Borges, 2011c: 585).

Por otra parte, Borges identifica la Musa de los griegos con «lo que los hebreos y Milton llamaron el Espíritu y lo que nuestra triste mitología llama lo Subconsciente», según explica en el Prólogo a La rosa profunda (Borges, 2011c: 385). Así ha de interpretarse el poema «El otro», de El otro, el mismo, en el que la mención al Espíritu procede de Juan 3, 8, donde Jesús dice que «el Espíritu sopla donde quiere» (Borges, 2011c: 199). En este caso, la libérrima interpretación del texto sagrado tiene que ver directamente con el propio acto de la creación literaria.

«El Golem» ${ }^{16}$, de El otro, el mismo, gira en torno a una tradición cabalística bien conocida: aquella que sostiene que la pronunciación exacta del Tetragrámaton, tal y como el pueblo judío la enseñó originalmente, traería consigo un poder sobrenatural. El protagonista del poema, el rabino Judá León, alcanza a pronunciar el nombre de Dios y labra un muñeco «para enseñarle los arcanos / de las Letras, del Tiempo y del Espacio» (Borges, 2011c: 194). También en relación con el judaísmo han de tenerse en cuenta los sonetos dedicados al filósofo Spinoza («Spinoza», de El otro, el mismo, y «Baruch Spinoza», de La moneda de hierro), por lo que esta figura tiene de heterodoxa: a los veintitrés años fue expulsado de la sinagoga, y una de sus principales obras, el Tractatus theologico-politicus, fue prohibida tanto por las autoridades holandesas como por la Inquisición de Roma (cf. MacCulloch, 2011: 833-834).

16 Vid. el prólogo de Jorge Luis Borges a la edición de El Golem, de Gustav Meyrink, que vio la luz en 1985 en la editorial Hyspamérica, dentro de una colección de títulos cuya selección estuvo a cargo del escritor argentino (prólogo recogido en Borges, 2011b: 321-322). 
Mencionaré por último los «Fragmentos de un evangelio apócrifo», de Elogio de la sombra, en el que Borges ofrece sus propias bienaventuranzas; «The Thing I Am» ${ }^{17}$, de Historia de la noche (1977), en el que el reverendo Haslam aparece «descifrando los versículos / de la Escritura» (Borges, 2011c: 508), en consonancia con el modo de entender la lectura individual de la Biblia que es propio de las iglesias nacidas de la Reforma; y «Las nubes», de Los conjurados, que expone la siguiente idea relativa a la relación de Dios con su creación:

¿Qué son las nubes? ¿Una arquitectura / del azar? Quizá Dios las necesita / para la ejecución de Su infinita / obra y son hilos de la trama oscura. / Quizá la nube sea no menos vana / que el hombre que la mira en la mañana (Borges, 2011c: 608).

\section{Conclusiones}

El 18 de junio de 1986, en la catedral reformada de San Pedro de Ginebra, un sacerdote católico y un pastor protestante oficiaron el funeral de Jorge Luis Borges, un gran escritor agnóstico que tuvo en los textos sagrados y en las creencias religiosas, especialmente cristianas, dos de sus fuentes de inspiración más notables. El conocimiento bíblico recibido de los Haslam a través de su abuela paterna, la tradición católica de su familia materna, así como su interés por el judaísmo y por la filosofía dieron como fruto la diversidad de sus referencias teológicas y, en buena medida, la complejidad de su universo poético. Dicha riqueza se evidencia, sobre todo, en los temas relacionados con la soteriología y la escatología. La poesía de Borges parece haber cumplido, literariamente, el deseo de ecumenismo manifestado en «Los conjurados», la composición que cierra su último libro de poemas.

El hecho de que Borges insistiera en abordar cuestiones relacionadas con el destino de los hombres, el más allá y el sentido último de las cosas, supuso el cauce propicio para que sus inquietudes teológicas afloraran en su poesía. O acaso fueron precisamente dichas inquietudes las que trajeron consigo el tratamiento de los temas mencionados. De cualquier forma, en las obras del autor encontramos versos que parecen propios de un agnóstico, otros que concuerdan con el pensamiento católico o con el protestante (sobre todo calvinista), y otros que, aun teniendo un trasfondo cristiano, expresan ideas que desde la perspectiva del cristianismo mayoritario resultan heterodoxas. Para comprender plenamente la poesía de Borges es necesario tener presente dicha diversidad.

\section{REFERENCIAS BIBLIOGRÁFICAS}

Aizenberg, E. (1986). El tejedor del Aleph: Biblia, Kábala y judaísmo en Borges. Madrid: Altalena.

Allin, T. et alii (1848). The jubilee of the Methodist New Connexion: being a grateful memorial of the origin, government, and history of the denomination. London: John Bakewell.

${ }^{17}$ En su parte final está el eco de Éxodo 3, 14, donde Dios se presenta a Moisés como «Yo soy el que soy», según la traducción convencional. 
Alonso SchöKel, L. (2001). Biblia del peregrino. Bilbao: Mensajero. 1. a ed. ${ }^{o} 1993$.

BARTH, K. (2004). Church dogmatics. Volumen II.2. Londres-Nueva York: T\&T Clark International. $1 .^{\text {a }}$ ed. $^{\circ} 1942 ; 1 .^{\text {a }}$ trad. inglesa 1957.

Bioy Casares, A. (2006). Borges. Barcelona: Destino.

Borges, J. L. (2011a). Cuentos completos. Barcelona: Lumen.

- (2011b). Miscelánea. Barcelona: Debolsillo.

- (2011c). Poesía completa. Barcelona: Lumen.

Bover, J. M., y F. Cantera (1947). Sagrada Biblia. Madrid: BAC.

Calvino, J. (2003). Institución de la religión cristiana. Tomo II. Madrid: Visor (Traducción de Cipriano de Valera, actualizada por la Fundación Editorial de Literatura Reformada de Rijswijk, Holanda). 1. ${ }^{\mathrm{a}}$ ed. ${ }^{\mathrm{o}}$ 1536; 1. ${ }^{\mathrm{a}}$ trad. española 1597.

Hadis, M. (2006). Literatos y excéntricos. Los ancestros ingleses de Jorge Luis Borges. Buenos Aires: Editorial Sudamericana.

KASSER, R. et alii (eds.) (2006). El Evangelio de Judas. Barcelona: RBA.

LÉONARD, E. (1967). Historia general del protestantismo. Tomo III. Barcelona: Edicions 62.

MacCulloch, D. (2011). Historia de la Cristiandad. Barcelona: Debate.

Nácar, E., y A. Colunga (1944). Sagrada Biblia. Madrid: Biblioteca de Autores Cristianos.

Piñero, A. (ed.) (2009). Todos los evangelios. Madrid: EDAF.

Reina, C. de, y C. DE VAlera (1862). La Santa Biblia. Oxford: Imprenta de la Universidad. 1. ${ }^{\text {a }}$ ed. ${ }^{\circ}$ 1602 (revisión de Cipriano de Valera de la traducción publicada por Casiodoro de Reina en 1569).

- (1909). La Santa Biblia. Madrid: Depósito Central de la Sociedad Bíblica B y E [Británica y Extranjera]. 1. ${ }^{\mathrm{a}}$ ed. ${ }^{\circ} 1602$ (revisión de Cipriano de Valera de la traducción publicada por Casiodoro de Reina en 1569).

Scío de San Miguel, F. (1797). La Biblia Vulgata Latina. Tomo primero del Nuevo Testamento. Barcelona: Jaime Seix.

Torres Amat, F. (1997). Sagrada Biblia. Traducción de la Vulgata Latina por el P. Petisco. Barcelona: Océano. 1. ${ }^{\mathrm{a}}$ ed. ${ }^{\circ}$ 1823-1825.

VV. AA. (1992). Catecismo de la Iglesia católica. Bilbao: Asociación de Editores del Catecismo.

VV. AA. (1853). Holy Bible. London: George E. Eyre y William Spottiswoode [King James version]. $1 .^{\mathrm{a}}$ ed. ${ }^{\mathrm{o}} 1611$.

White, P. (2002). Predestination, policy and polemic: conflict and consensus in the English Church from de Reformation to the Civil War. Cambridge: Cambridge University Press.

Wurst, G. (2006). «Ireneo de Lyon y el Evangelio de Judas». En El Evangelio de Judas, R. Kasser et alii (eds.), 113-125. Barcelona: RBA. 